\title{
Current management of severe acquired aplastic anemia
}

\author{
Tratamento atual da anemia aplástica adquirida grave \\ Phillip Scheinberg ${ }^{1}$
}

\begin{abstract}
Overall survival in severe aplastic anemia has markedly improved in the past four decades due to advances in stem cell transplantation, immunosuppressive therapies and supportive care. Horse anti-thymocyte globulin plus cyclosporine is the standard immunosuppressive regimen in severe aplastic anemia, and often employed as initial therapy as most are not candidates for a matched related stem cell transplantation. With this regimen, hematologic response can be achieved in 60 to $70 \%$ of cases, but relapse is observed in 30 to $40 \%$ of responders and clonal evolution in 10 to $15 \%$ of patients. Efforts to improve outcomes beyond horse anti-thymocyte globulin plus cyclosporine have been disappointing, with no significant improvement in the critical parameter of hematologic response, which strongly correlates with long-term survival in severe aplastic anemia. Furthermore, rates of relapse and clonal evolution have also not improved with the development of three drug regimens or with more lymphocytotoxic therapies. Therefore, horse anti-thymocyte globulin plus cyclosporine remains the standard immunosuppression of choice as first therapy in severe aplastic anemia. Interestingly, survival has markedly improved over the years in large part due to better anti-infective therapy and more successful salvage therapies with immunosuppression and stem cell transplantation. In this review general aspects of diagnosis and management are discussed.
\end{abstract}

Keywords: Anemia, aplastic/diagnosis; Anemia, aplastic/drug therapy; Hematopoietic stem cell transplantation; Immunosuppressive agents/therapeutic use

\section{RESUMO}

A sobrevida em pacientes com grave anemia aplástica melhorou muito nas últimas quatro décadas. Isso se deve a progressos no transplante de células hematopoiéticas, terapias imunossupressoras e terapia de suporte. 0 tratamento padrão imunossupressivo é 0 uso de ciclosporina mais globulina antitimocítica de soro de cavalo, terapêutica que é frequentemente a inicial, pois a maior parte dos pacientes não dispõe de parente HLA compatível para transplante de células hematopoiéticas relacionadas. Com esse esquema, remissões são obtidas em 60 a 70\% dos casos, mas recaídas se seguem em 30 a $40 \%$ dos respondedores e há evolução clonal em 10 a $15 \%$ dos pacientes. Tentativas de melhorar os resultados com outras terapias, além de ciclosporina e globulina antitimocítica, têm sido desapontadoras, sem melhora significativa nos resultados dos parâmetros hematológicos críticos de resposta, que se correlacionam à sobrevida a longo prazo em anemia aplástica grave. As percentagens de recaída e de evolução clonal não melhoram com a introdução de esquemas com três drogas ou mais terapêuticas linfotóxicas. Assim, ciclosporina e globulina antitimocítica permanecem o tratamento padrão de primeira escolha para anemia aplástica grave. Cabe apontar que a sobrevida melhorou muito no decorrer do tempo, graças, em boa parte, a melhoras na terapia anti-infecciosa e aos melhores resultados de terapia de salvage, com imunussupressão e transplante de células hematopoiéticas. Nesta revisão são apresentados aspectos gerais de diagnósticos e de tratamento.

Descritores: Anemia aplástica/diagnóstico; Anemia aplástica/ quimioterapia; Transplante de células-tronco hematopoiéticas; Agentes imunossupressores/uso terapêutico

\section{INTRODUCTION}

Severe aplastic anemia (SAA) has evolved from a disease with a high fatality rate in the 1960s to one in which long-term survival can be achieved in the majority of patients after diagnosis ${ }^{(1)}$. Pancytopenia is characteristic and bone marrow is classically empty as a result of significant diminution of hematopoietic stem and progenitors cells. Current clinical and laboratory evidence supports an immune pathophysiology in which effector cells and related cytokines recognize and destroy primitive elements of the bone marrow ${ }^{(2)}$. Hematopoiesis can be restored in SAA with stem cell transplantation(SCT) orimmunosuppressive therapy ${ }^{(2)}$. The majority of patients are not candidates for a matched related SCT due to lack of a histocompatible sibling, age, comorbidities or inaccessibility to transplant; therefore, immunosuppression is the most

\footnotetext{
Hematology Branch, National Heart, Lung, and Blood Institute - Bethesda, MD, USA.

Corresponding author: Phillip Scheinberg - 10 Center Drive, Building 10 CRC - Room 3E-5140, MSC 1202 - Bethesda, MD, USA, 20892-1202 - E-mail: scheinberg@mail.nih.gov

The author declares there is no conflict of interest.

Received on: Jan 10, 2011 - Accepted on: April 5,2011
} 
widely employed treatment modality worldwide in SAA.

The most well-studied immunosuppressive regimens in SAA have been based on anti-thymocyte globulin (ATG). Currently there are two commercially available preparations of ATG, one derived from horse and the other from rabbit. ATG is produced by stimulating an animal with $\mathrm{T}$ cells derived from the human thymus or cell lines, which results in the production of xenogeneic polyclonal antibodies that recognize several molecules expressed on the surface of the $\mathrm{T}$ lymphocyte. The serum is then purified to remove red cell contamination and complement is deactivated. Although the manufacturing of both ATGs are similar, important distinct biologic activities have been shown in vitro and in vivo, suggesting that there are different effects among these agents on the human immune system ${ }^{(3,4)}$.

The standard regimen in SAA is with horse ATG plus cyclosporine (CsA), which produces hematologic recovery in 60 to $70 \%$ of cases and very good long term survival in particular among responders ${ }^{(2)}$. However, hematologic relapse occurs in 30 to $40 \%$ of responders and clonal evolution to myeodysplasia in 10 to $15 \%{ }^{(5)}$. Therefore, the occurrence of these two late events limits the success of horse ATG/ CsA in the clinic. Several attempts have been made to improve beyond standard horse ATG/CsA but to date none have been shown superior. The addition of a third agent to standard horse ATG/CsA such as G-CSF, androgens, mycophenolate mofetilor sirolimus have not resulted in better hematologic response and survival outcomes ${ }^{(6-9)}$. Furthermore, more potent lymphocytotoxic agents such as cyclophosphamide, rabbit ATG, and alemtuzumab have not performed better than horse ATGin randomized controlled trials ${ }^{(10-}$ 12). Thus, despite these efforts, horse ATG/CsA remains the standard regimen in SAA. In this brief review some of the practical aspects in the management of SAA and recent data will be discussed.

\section{DISEASE PRESENTATION AND DIAGNOSIS OF SAA}

Patients with SAA often seek medical attention due to complications from pancytopenia. Symptoms derive from low blood counts. Anemia leads to fatigue, weakness, headaches, and dyspnea. Thrombocytopenia produces mucocutaneous bleeding with frequent complaints being petechiae, epistaxis and gingival bleeding. Although infrequent, the most concerning complication of thrombocytopenia is intracranial hemorrhage. Bacterial and fungal infections in the setting of neutropenia are a major cause of morbidity and mortality, and require immediate medical intervention. Constitutional symptoms, lymphadenomegaly or organomegaly are not characteristic of SAA and suggest another diagnosis. Symptoms can occur from days to weeks before a blood test is performed and pancytopenia detected. Severe pancytopenia is generally defined as having two of the following three peripheral blood count criteria: absolute neutrophil count $<500 / \mathrm{mL}$, platelet count $<20,000 / \mathrm{mL}$, and absolute reticulocyte count $<$ $60,000 / \mathrm{mL}^{(13)}$.

Severe aplastic anemia is a diagnosis of exclusion and the main distinction to be made is with other primary marrow diseases. In SAA, cellularity is always reduced for age $(<30 \%)$ but areas of patchy cellularity (so called "hot spots") can sometimes be present. Secondary causes of pancytopenia (autoimmune diseases, vitamin deficiencies, hypersplenism, alcoholism, certain infections etc.) can often be excluded by routine history, physical examination and laboratory testing. Single lineage cytopenia with a decrease in the corresponding marrow progenitor population suggests pure red cell aplasia (anemia, reticulocytopenia, and absent erythroid marrow precursors), agranulocytosis (neutropenia, relevant drug exposure, and absent granulocytic marrow precursors), or amegakaryocytic thrombocytopenic purpura (thrombocytopenia and absent marrow megakaryocytes). Marrow fibrosis, organomegaly, and leukoerythroblastosis suggest myelofibrosis. In rare instances leukemias can present with a hypocellular marrow therefore careful examination of the spicules for blasts is important. In those with a more indolent course of cytopenia and a cellular marrow, flow cytometric assay and T-cell gene rearrangement studies may reveal a clonal population suggestive of large granular lymphocytic leukemia.

The more difficult distinction is between SAA and myelodysplasia, which can present with a hypocellular marrow in about $20 \%$ of cases ${ }^{(14)}$. Dysplastic changes in SAA are often modest with more striking findings present in myelodysplasia. In SAA, bone marrow cytogenetics is almost always normal while in myelodysplasia, frequently abnormal. A paroxysmal nocturnal hemoglobinuria $(\mathrm{PNH})$ clone, characterized by red blood cells and neutrophils deficient in glycosylphosphatidilinositol anchored proteins (e.g., CD55 and CD59) can be detected at presentation by flow cytometry in about 40 to $50 \%$ of SAA (AA/PNH) and in about $20 \%$ of patients with myelodysplasia ${ }^{(14)}$. In these cases, clone size is often small and hemolysis may be undetectable (especially in transfused cases) and thrombosis unusual. The clone size can expand over time and lead to more significant clinical hemolysis. Primary PNH occurs when the degree of 
cytopenia is not severe and the clinical symptoms are dominated by severe hemolysis (manifested by anemia, elevated lactate dehydrogenase level and dark urine), esophageal spasm, abdominal pain and/or complications of thrombosis (Budd-Chiari, deep vein thrombosis, and strokes).

In a subset of patients, mutations in telomerase genes have been identified ${ }^{(15,16)}$. An intact telomerase complex is essential to counter the erosion of chromosome ends (telomeres) that occur naturally with each cell division. Cells with a very high proliferative potential (such as lymphocytes and hematopoietic stem cells) rely on elongation of the telomeric ends (by the telomerase complex) to prevent critical shortening of the telomeres and its consequence, replicative senescence and cell death. Mutations in the RNA component (encoded by $T E R C$ ) and the catalytic subunit (encoded by TERT) of this complex have been classically associated to inherited forms of marrow failure, such as dyskeratosis congenita ${ }^{(17)}$. However, the stigmata commonly associated to dyskeratosis congenita (short stature, nail dystrophy, oral leukoplakia) is lacking in these patients with "acquired" SAA ${ }^{(16)}$. In these cases, telomere length is often very short in the first decile. The impact of these findings in the clinic for this subset of patients is not yet understood. A shorter age-adjusted telomere length has not been associated to response to immunosuppression, however, a strong correlation with late events of hematologic relapse and clonal evolution have been observed ${ }^{(18)}$. In addition, in SAA patients who carry a mutation in telomerase genes, response to immunosuppression has been observed. Therefore, the proper incorporation of these findings in the clinic should await validation from prospective studies.

\section{MANAGEMENT OF SAA}

\section{Treatment modality}

Once a diagnosis of SAA is established, the initial managementincludeseitherSCTorimmunosuppressive therapy. Both are considered definitive therapies with comparable long-term survival outcomes ${ }^{(2)}$. In children and young adults with a histocompatible sibling, a matched sibling SCT is the preferred first therapy, in older patients (over 30 to 40 years of age) or in those who lack a histocompatible sibling, immunosuppression is the initial therapy of choice. Alternative donor SCT should only be considered in the salvage setting after immunosuppression in those who remain refractory or who experience late complications of relapse or clonal evolution.

Although survival after a matched unrelated donor SCT has improved in recent years ${ }^{(19,20)}$, experience from large registry studies suggests that outcomes are still inferior to those of a matched related $\mathrm{HSCT}^{(21-}$

23). Graft-versus-host disease, engraftment (in older patients) ${ }^{(24)}$, and infectious are still problematic complications. More recently long-term outcome for pediatric patients undergoing immunosuppressive therapy with horse ATG/CsA has been reported: long-term survival for all patients was about $80 \%$ and among those who responded to immunosuppression, at about $90 \%{ }^{(25)}$. Therefore, in view of these excellent results, children who lack a matched sibling should receive immunosuppression as first therapy.

Peripheral blood mobilized $\mathrm{CD}_{3}{ }^{+}$cells have gained popularity as a stem cell source in several transplant centers since the late 1990s in large part due to the less invasive collection process. However, in the last 5 years, increased incidence of graft-versushost disease has been reported in SAA compared to historical rates with bone marrow derived stem cells ${ }^{(26)}$. These results have been recently confirmed by studies in the American registry(27), corroborating the notion that incidence of graft-versus-host disease with G-CSF mobilized stem cells was worst than bone marrow derived progenitor cells. As there is no benefits of graft-versus-host disease in SAA transplant outcomes, bone marrow should be the preferred source of stem cells in patients with SAA undergoing SCT.

\section{INITIAL IMMUNOSUPPRESSIVE THERAPY}

The standard immunosuppressive regimen in SAA is with horse ATG plus cyclosporine once this combination was shown to be superior to horse ATG alone in a randomized trial reported 20 years ago ${ }^{(28)}$. Since then, there has been a very large experience with this regimen across large studies in the United States, Europe, and Japan (Table 1). In the past two decades, several alternative regimens were developed to improve beyond horse ATG/CsA with limited success. Probably one of the most well-studied regimens included the addition of G-CSF to standard horse $\mathrm{ATG} / \mathrm{CsA}^{(8,9,29,30)}$. Although a shorter duration of neutropenia and fewer infectious complications were reported in the G-CSF treated patients, there was no difference in hematologic response or survival rate compared tohorse ATG/CsAwithoutG-CSF.Inarecently reported large randomized study including 192 patients again no differences in response and survival were observed when G-CSF was added to standard horse ATG/ $\mathrm{CsA}^{(9)}$. Therefore, data from several prospective studies does not support the routine use of G-CSF with horse ATG/CsA in SAA.

The addition of a third immunosuppressive agent to horse ATG/CsA although rational, did not improve 
Table 1. Immunosuppression studies based on horse antitimic globulin/ciclosporin in severe aplastic anemia

\begin{tabular}{|c|c|c|c|c|c|c|c|}
\hline Study & Years & $n$ & Median Age (years) & Response (\%) & Relapse (\%) & Clonal evolution (\%) & Survival \\
\hline German $^{(28)}$ & 1986-1989 & 84 & 32 & 65 & 19 & 8 & $58 \%$ at 11 years \\
\hline $\mathrm{NIH}^{(5)}$ & 1991-1998 & 122 & 35 & 61 & 35 & 11 & $55 \%$ at 7 years \\
\hline $\mathrm{EGBMT}^{(42)}$ & 1991-1998 & 100 & 16 & 77 & 12 & 11 & $87 \%$ at 5 years \\
\hline $\operatorname{Japan}^{(8)}$ & 1992-1997 & 119 & 9 & 68 & 22 & 6 & $88 \%$ at 3 years \\
\hline German/Austrian ${ }^{(43)}$ & 1993-1997 & 114 & 9 & 77 & 12 & 6 & $87 \%$ at 4 years \\
\hline $\operatorname{Japan}^{(30)}$ & $1996-2000$ & 101 & 54 & 74 & 42 & 8 & $88 \%$ at 4 years \\
\hline$N H^{(7)}$ & 2003-2005 & 77 & 26 & 57 & 26 & 10 & $93 \%$ at 3 years \\
\hline $\mathrm{NIH}^{(11)}$ & $2005-2010$ & 120 & 28 & 68 & 28 & 21 & $96 \%$ at 3 years \\
\hline
\end{tabular}

NIH: National Institutes of Health; EGBMT: European Group for Blood \& Marrow Transplantation.

outcomes in SAA. In a study of over one hundred patients, the addition of mycophenolate mofetil to horse ATG/ CsA did not improve the response, relapse and clonal evolution rates compared to historical controls ${ }^{(6)}$, and in a prospective randomized study, the addition of sirolimus to horse ATG/CsA was not superior to the same regimen without sirolimus ${ }^{(7)}$. More controversial has been the use of cyclophosphamide in SAA. The activity of this agent in SAA was first reported about 40 years ago $^{(31)}$ but the larger experience with this regimen reported only in the past 10 to 15 years $^{(32)}$. However, when directly compared to standard horse ATG/CsA in a randomized trial, cyclophosphamide was excessively toxic leading to severe life-threatening fungal complications and deaths, resulting in early termination of the study ${ }^{(10)}$. To date, the favorable experience with cyclophosphamide in SAA has not been reproduced outside a single center casting doubts on the generalizability of this experience. It is particularly difficult to exclude patient selection bias (exclusion of those unlikely to respond, with poor prognosis, older, uninsuredetc.)intheHopkinsexperience which likely accounts for the significant differences in outcomes observed with this regimen. Therefore, cyclophosphamide should be considered experimental and administered in SAA only in the context of a clinical research protocol.

The addition of more lymphocytotoxic agents have also been disappointing. Alemtuzumab when given as first therapy was inferior to standard horse ATG/CsA in a randomized study and its use was therefore discontinued inthissetting ${ }^{(12)}$. Moreimportantly,rabbitATG/CsA, which has been successful in the salvage setting, performed poorly when directly compared to horse ATG/CsA in a prospective randomized trial ${ }^{(11)}$. The hematologic response to rabbit ATG was 30\% lower than horse ATG, which resulted in about a $20 \%$ lower survival rate ${ }^{(11)}$. It is important to note that the study was developed 6 years ago to show the opposite, that rabbit ATG be a superior regimen compared to horse ATG.
Therefore, horse ATG/CsA should remain the immunosuppressive regimen of choice as first therapy in SAA. The findings from this study were unanticipated and have immediate impact on patient care in Europe, Asia and South America were horse ATG is not available.

\section{MANAGEMENT IN THE SALVAGE SETTING}

\section{Refractory SAA}

Inpatientsunresponsivetoinitialhorse ATG/CsA,treatment options include a repeat course of immunosuppression or SCT in suitable candidates. In children and young adults with a histocompatible unrelated donor (10/10), SCT is a viable option. For all other patients, a repeat course of immunosuppression is generally recommended. There is a greater experience with rabbit ATG/CsA in this setting which produces hematologic response rate that has variedfrom 30 to $77 \%{ }^{(12,33,34)}$. More recently, alemtuzumab monotherapy (without cyclosporine) has shown similar activity in refractory SAA and is an alternative in those who tolerated ATG and/or cyclosporine poorly or in older patients $^{(12)}$. In patients who remain refractory to two courses of immunosuppression, a third course is unlikely to be of benefit, unless there is evidence of increment in blood counts with prior courses ${ }^{(35)}$. In these cases, non-immunosuppressive options can be tried such as a course of male hormones or growth factors for 3 months. In persistent refractory patients with a very low neutrophil count, more risky transplant modalities from mismatched unrelated, umbilical cord of haploidentical donors can be considered. It is important to note that in the absence of very severe neutropenia and/or lifethreatening infections, most patients can be supported (transfusions and growth factors) for years, albeit with an impact in quality of life. In these cases, proper iron chelation should be instituted to prevent long-term complications of iron overload. With advances in the antifungalarmamentarium and supportive care in the past decade, survival in those refractory patients has markedly 
improved over the years ${ }^{(1)}$. Therefore, the conduct in those who remain unresponsive to immunosuppression should be individualized taking into consideration age, comorbidities, neutrophil count, donor availability, infectious history, degree of transfusion support, and patient preference.

\section{Relapsed SAA}

In patients who relapse, improvement in blood counts can often be achieved with more immunosuppression. Despite the need for more therapy, relapse has not been associated to worst survival in $\mathrm{SAA}^{(5)}$. In these cases, re-introduction of oral cyclosporine for 3 months can be effective. Rabbit ATG plus CsA has been shown to produce response rates of about 50 to $60 \%$ in this setting across several studies ${ }^{(33,36)}$. In a more recent experience, alemtuzumab without cyclosporine showed a response rate of about $55 \%$ in relapsed SAA, suggesting that it is a viable option in this setting as well ${ }^{(12)}$.

\section{Clonal evolution}

The acquisition of karyotype abnormalities represents the most concerning late complication in SAA. In particular, monosomy 7 associates to refractoriness to immunosuppression, falling counts, and progression to leukemia ${ }^{(37)}$. However, not all cytogenetic abnormalities carry the same dire outcome. Trisomy 8 has not been associated to worst survival and a higher rate of responsiveness to immunosuppression is likely in these patients ${ }^{(37)}$. Therefore, the interpretation of a new cytogenetic finding should be placed into clinical context. For example, in a patient who has a new cytogenetic abnormality identified along with falling counts and new dysplastic changes in the marrow, evolution to myelodysplasia is more likely. However, when a karyotype abnormality is detected in the setting of stable counts and no new dysplastic findings, its interpretation becomes less clear. In these cases, close monitoring of blood counts, bone marrow morphology and cytogenetics becomes important to better define the impact of the karyotype finding. On occasion, cytogenetic abnormalities may be transient and not necessarily represent a myelodysplastic transformation. One exception is the identification of a monosomy 7 karyotype, which almost always correlates with dysplastic findings in the marrow and progressive disease.

Unfortunately there are no good treatment options in those who evolve to myelodysplasia, with the only definitive therapy being SCT. In those who are suitable candidates, HSCT should be pursued from a matched sibling (preferred) or unrelated donor. Hypomethylating drugs may be a therapeutic option but there's limited experience with these agents in myelodysplasia that evolved from SAA. Nevertheless, this strategy is not perceived as definitive therapy in most cases. In those who are not transplant candidates and remain unresponsive to hypomethylating agents, enrollment into a clinical trial should be considered.

\section{CONCLUDING REMARKS}

Nowadays, the majority of patients are expected to be alive years after the diagnosis of $\mathrm{SAA}^{(1)}$. With one or two courses of immunosuppression, hematologic response rate can be achieved in 75 to $90 \%$ of cases, which closely correlates to long-term survival. As horse ATG is not available outside the United States, the hematology community will have to work with regulatory agencies in Europe, Asia and South America to address the lack of the superiorimmunosuppressive regimenfor SAA patientsin these markets.

The timing of HSCT and role of alternative donor HSCTare evolvingandwill require prospectivevalidation. Parameters that are predictive of response and survival such as the pre-treatment absolute reticulocyte are likely to contribute in individualized risk assessment in SAA ${ }^{(38-}$

${ }^{41)}$. It is likely that future algorithms in SAA will include predictors of outcomes that better risk stratifies patients allowing for more tailored therapies.

\section{ACKNOWLEDGEMENTS}

This research was supported by the Intramural Research Program of the National Institutes of Health, National Heart, Lung and Blood Institute.

\section{REFERENCES}

1. Valdez JM, Scheinberg P, Nunez O, Wu CO, Young NS, Walsh TJ. Decreased infection-related mortality and improved survival in severe aplastic anemia in the past two decades. Clin Infect Dis. 2011;52(6):726-35.

2. Young NS, Calado RT, Scheinberg P. Current concepts in the pathophysiology and treatment of aplastic anemia. Blood. 2006;108(8):2509-19.

3. Feng X, Kajigaya S, Solomou EE, Keyvanfar K, Xu X, Raghavachari $N$, et al. Rabbit ATG but not horse ATG promotes expansion of functional CD4+CD25highFOXP3 + regulatory $\mathrm{T}$ cells in vitro. Blood. 2008; $111(7): 3675-83$

4. Scheinberg P, Fischer SH, Li L, Nunez O, Wu CO, Sloand EM, et al. Distinct EBV and CMV reactivation patterns following antibody-based immunosuppressive regimens in patients with severe aplastic anemia. Blood. 2007;109(8):3219-24.

5. Rosenfeld S, Follmann D, Nunez O, Young NS. Antithymocyte globulin and cyclosporine for severe aplastic anemia: association between hematologic response and long-term outcome. JAMA. 2003;289(9):1130-5.

6. Scheinberg P, Nunez 0, Wu C, Young NS. Treatment of severe aplastic anaemia with combined immunosuppression: anti-thymocyte globulin, ciclosporin and mycophenolate mofetil. Br J Haematol. 2006;133(6):60611. 
7. Scheinberg P, Wu CO, Nunez O, Scheinberg P, Boss C, Sloand EM, et al. Treatment of severe aplastic anemia with a combination of horse antithymocyte globulin and cyclosporine, with or without sirolimus: a prospective randomized study. Haematologica. 2009;94(3):348-54.

8. Kojima S, Hibi S, Kosaka Y, Yamamoto M, Tsuchida M, Mugishima H, et al. Immunosuppressive therapy using antithymocyte globulin, cyclosporine, and danazol with or without human granulocyte colony-stimulating factor in children with acquired aplastic anemia. Blood. 2000;96(6):2049-54.

9. Tichelli A, Schrezenmeier H, Socié G, Marsh J, Bacigalupo A, Dührsen U, et al. A randomized controlled study in newly-diagnosed severe aplastic anemia patients receiving antithymocyte globulin (ATG), cyclosporine, with or without G-CSF: a study of the SAA Working Party of the EBMT. Blood. 2011;117(17):4434-41.

10. Tisdale JF, Dunn DE, Geller N, Plante M, Nunez O, Dunbar CE, et al. Highdose cyclophosphamide in severe aplastic anaemia: a randomised trial. Lancet. 2000;356(9241):1554-9.

11. Scheinberg P, Wu CO, Scheinberg P, Weinstein B, Nunez O, Sloand EM, et al. A Randomized Trial of Horse Versus Rabbit Antithymocyte Globulin In Severe Acquired Aplastic Anemia. ASH Annual Meeting Abstracts. 2010;116:LBA-4-.

12. Scheinberg P, Wu CO, Scheinberg P, Nunez O, Sloand EM, Young NS. Alemtuzumab (Campath) Monotherapy for Severe Aplastic Anemia. ASH Annual Meeting Abstracts. 2010;116:1167.

13. Rosenfeld SJ, Kimball J, Vining D, Young NS. Intensive immunosuppression with antithymocyte globulin and cyclosporine as treatment for severe acquired aplastic anemia. Blood. 1995;85(11):3058-65.

14. Scheinberg P, Marte M, Nunez 0, Young NS. Paroxysmal nocturnal hemoglobinuria clones in severe aplastic anemia patients treated with horse anti-thymocyte globulin plus cyclosporine. Haematologica. 2010;95(7):1075-80.

15. Yamaguchi H, Calado RT, Ly H, Kajigaya S, Baerlocher GM, Chanock SJ, et al. Mutations in TERT, the gene for telomerase reverse transcriptase, in aplastic anemia. N Engl J Med. 2005;352(14):1413-24.

16. Fogarty PF, Yamaguchi H, Wiestner A, Baerlocher GM, Sloand E, Zeng WS, et al. Late presentation of dyskeratosis congenita as apparently acquired aplastic anaemia due to mutations in telomerase RNA. Lancet. 2003;362(9396):1628-30.

17. Vulliamy T, Marrone A, Goldman F, Dearlove A, Bessler M, Mason PJ, et al. The RNA component of telomerase is mutated in autosomal dominant dyskeratosis congenita. Nature. 2001;413(6854):432-5.

18. Scheinberg P, Cooper JN, Sloand EM, Wu CO, Calado RT, Young NS. Association of Telomere Length of Peripheral Blood Leukocytes With Hematopoietic Relapse, Malignant Transformation, and Survival in Severe Aplastic Anemia. JAMA. 2010;304(12):1358-64.

19. Kennedy-Nasser AA, Leung KS, Mahajan A, Weiss HL, Arce JA, Gottschalk $S$, et al. Comparable outcomes of matched-related and alternative donor stem cell transplantation for pediatric severe aplastic anemia. Biol Blood Marrow Transplant. 2006;12(12):1277-84.

20. Bacigalupo A, Socie' G, Lanino E, Prete A, Locatelli F, Locasciulli A, Cesaro S, Shimoni A, Marsh J, Brune M, Van Lint MT, Oneto R, Passweg J; Severe Aplastic Anemia Working Party of the European Group for Blood and Marrow Transplantation. Fludarabine, cyclophosphamide, antithymocyte globulin, with or without low dose total body irradiation, for alternative donor transplants, in acquired severe aplastic anemia: a retrospective study from the EBMT-SAA working party. Haematologica. 2010;95(6):976-82

21. Passweg JR, Pérez WS, Eapen M, Camitta BM, Gluckman E, Hinterberger $W$, et al. Bone marrow transplants from mismatched related and unrelated donors for severe aplastic anemia. Bone Marrow Transplant. 2006;37(7):641-9.

22. Deeg HJ, O'Donnell M, Tolar J, Agarwal R, Harris RE, Feig SA, et al. Optimization of conditioning for marrow transplantation from unrelated donors for patients with aplastic anemia after failure of immunosuppressive therapy. Blood. 2006;108(5):1485-91.

23. Perez-Albuerne ED, Eapen M, Klein J, Gross TJ, Lipton JM, Baker KS, et al. Outcome of unrelated donor stem cell transplantation for children with severe aplastic anemia. $\mathrm{Br} J$ Haematol. 2008;141(2):216-23.24. Bacigalupo A, Locatelli F, Lanino E, Marsh J, Socié G, Maury S, Prete A, Locasciulli A, Cesaro S, Passweg J; Severe Aplastic Anemia Working Party of the European Group for Blood and Marrow Transplantation. Fludarabine, cyclophosphamide and anti-thymocyte globulin for alternative donor transplants in acquired severe aplastic anemia: a report from the EBMTSAA Working Party. Bone Marrow Transplant. 2005;36(11):947-50.

25. Scheinberg P, Wu CO, Nunez O, Young NS. Long-term outcome of pediatric patients with severe aplastic anemia treated with antithymocyte globulin and cyclosporine. J Pediatr. 2008;153(6):814-9.

26. Schrezenmeier H, Passweg JR, Marsh JC, Bacigalupo A, Bredeson CN, Bullorsky $\mathrm{E}$, et al. Worse outcome and more chronic GVHD with peripheral blood progenitor cells than bone marrow in HLA-matched sibling donor transplants for young patients with severe acquired aplastic anemia. Blood. 2007;110(4):1397-400.

27. Chu R, Brazauskas R, Kan F, Bashey A, Bredeson C, Camitta B, et al. Comparison of Outcomes after Transplantation of G-CSF-Stimulated Bone Marrow Grafts versus Bone Marrow or Peripheral Blood Grafts from HLAMatched Sibling Donors for Patients with Severe Aplastic Anemia. Biol Blood Marrow Transplant. 2010 Oct 27. Epub ahead of print.

28. Frickhofen N, Kaltwasser JP, Schrezenmeier H, Raghavachar A, Vogt HG, Herrmann F, et al. Treatment of aplastic anemia with antilymphocyte globulin and methylprednisolone with or without cyclosporine. The German Aplastic Anemia Study Group. N Engl J Med. 1991;324(19):1297-304.

29. Gluckman E, Rokicka-Milewska R, Hann I, Nikiforakis E, Tavakoli F, Cohen-Scali S, Bacigalupo A; European Group for Blood and Marrow Transplantation Working Party for Severe Aplastic Anemia. Results and follow-up of a phase III randomized study of recombinant humangranulocyte stimulating factor as support for immunosuppressive therapy in patients with severe aplastic anaemia. $\mathrm{Br} \mathrm{J}$ Haematol. 2002;119(4):1075-82.

30. Teramura M, Kimura A, Iwase S, Yonemura Y, Nakao S, Urabe A, et al. Treatment of severe aplastic anemia with antithymocyte globulin and cyclosporin A with or without G-CSF in adults: a multicenter randomized study in Japan. Blood. 2007;110(6):1756-61.

31. Baran DT, Griner PF, Klemperer MR. Recovery from aplastic anemia after treatment with cyclophosphamide. N Engl J Med. 1976;295(27):1522-3.

32. Brodsky RA, Sensenbrenner LL, Smith BD, Dorr D, Seaman PJ, Lee SM, et al. Durable treatment-free remission after high-dose cyclophosphamide therapy for previously untreated severe aplastic anemia. Ann Intern Med. 2001;135(7):477-83.

33. Scheinberg P, Nunez O, Young NS. Retreatment with rabbit anti-thymocyte globulin and ciclosporin for patients with relapsed or refractory severe aplastic anaemia. Br J Haematol. 2006;133(6):622-7.

34. Di Bona E, Rodeghiero F, Bruno B, Gabbas A, Foa P, Locasciulli A, et al. Rabbit antithymocyte globulin ( $r$-ATG) plus cyclosporine and granulocyte colony stimulating factor is an effective treatment for aplastic anaemia patients unresponsive to a first course of intensive immunosuppressive therapy. Gruppo Italiano Trapianto di Midollo Osseo (GITMO). Br J Haematol. 1999;107(2):330-4

35. Gupta V, Gordon-Smith EC, Cook G, Parker A, Duguid JK, Wilson KM, et al. A third course of anti-thymocyte globulin in aplastic anaemia is only beneficial in previous responders. Br J Haematol. 2005;129(1):110-7.

36. Schrezenmeier H, Marin P, Raghavachar A, McCann S, Hows J, Gluckman $E$, et al. Relapse of aplastic anaemia after immunosuppressive treatment: a report from the European Bone Marrow Transplantation Group SAA Working Party. Br J Haematol. 1993;85(2):371-7. 
37. Maciejewski JP, Risitano A, Sloand EM, Nunez O, Young NS. Distinct clinical outcomes for cytogenetic abnormalities evolving from aplastic anemia. Blood. 2002;99(9):3129-35.

38. Gluckman E, Devergie A, Poros A, Degoulet P. Results of immunosuppression in 170 cases of severe aplastic anaemia. Report of the European Group of Bone Marrow Transplant (EGBMT). Br J Haematol. 1982;51 (4):541-50.

39. Chang MH, Kim KH, Kim HS, Jun HJ, Kim DH, Jang JH, et al. Predictors of response to immunosuppressive therapy with antithymocyte globulin and cyclosporine and prognostic factors for survival in patients with severe aplastic anemia. Eur J Haematol. 2010;84(2):154-9

40. Scheinberg $P$, Wu CO, Nunez 0 , Young NS. Predicting response to immunosuppressive therapy and survival in severe aplastic anaemia. $\mathrm{Br} \mathrm{J}$ Haematol. 2009;144(2):206-16.

41. Afable M, Shaik M, Sugimoto $Y$, Clemente M, Tui RV, Mohan SR, et al. Efficacy of Rabbit Anti-Thymocyte Globulin (ATG) Compared to Horse ATG in Severe Aplastic Anemia. ASH Annual Meeting Abstracts. 2010;116:2236. 